\title{
LIBERTAD, HUMANO TESORO *
}

\section{Huella del Cautiverio en la literatura cervantina}

Nos hemos reunido estos días finales del gélido otoño de 1993 para definir y aclarar la huella indiscutible del cautiverio argelino en la creación literaria cervantina. En términos generales, lo que tuvo de positivo el encuentro de Cervantes con la cultura musulmana. Pero, evidentemente, esa cultura no fue asimilada en su complejidad por nuestro escritor durante los cinco anos de cautiverio en Argel, sino que ya estaba impregnado de ella a través de la propia cultura materna y espanola, real y verdaderamente híbrida y mestiza. O aljamiada y mudéjar, si se prefiere recurrir a los términos de la tradición medieval. Que no en balde convivieron durante cerca de ocho siglos en la Península Ibérica los moros mahometanos y los hispano-godos cristianos con algunas comunidades judías, si menores en número, de gran importancia cultural y económica. Las tres religiones del Libro.

Entre las conclusiones de Ángel Ganivet en su Idearium espanol (1896), publicado en vísperas del desastre del 98, se afirmaba que nuestro tipo nacional por excelencia, el Ulises español, es Don Quijote, liberado del peso de las preocupaciones materiales, descargadas todas sobre el escudero Sancho Panza. «Sin los ára-

* El presente trabajo fue leído en la Fundación Cultural Banesto, de Madrid, el día 14 de diciembre de 1993, durante las Jornadas Cervantinas organizadas por el Instituto Internacional del Teatro del Mediterráneo, que dirige José Monleón. Por su tema, nos ha parecido oportuno traerlo a las páginas de Anales para su conocimiento en la esfera especifica de los cervantistas. 
bes” -sostenía ya Ganivet- «Don Quijote y Sancho hubieran sido siempre un solo hombre, un remedo de Ulises" '.

\section{MAUROFILIA LITERARIA}

Durante el siglo xvi florece en España una literatura morisca -narraciones en prosa, romances épico-líricos, piececillas dramáticas- de clara simpatía hacia los moros, convertidos o no a la fe cristiana, y transfigurados en paradigmas de valor, honor, fidelidad amorosa, y otras cualidades anteriormente reservadas sólo para los cristianos.

Los enemigos de ayer convivían ahora, en forzada o espontánea concordia, como campesinos y braceros de la tierra, en las aldeas del interior o en pueblecitos costeros de Levante y Andalucía, con los labradores «cristianos viejos». Y en las ciudades del interior, castellanas o aragonesas, en ocupaciones de artesanía doméstica y familiar.

La popular maurofilia de la literatura española en la Edad de Oro se acentúa en la obra de Cervantes. Ahí tenemos a Don Quijote, de regreso en su primera salida, transfigurado en el enamorado y leal Abindarráez, y su hermosa Jarifa convertida en la «linda Dulcinea del Toboson (DQ, I, 5). Tenemos la satisfacción de contar, en estas reuniones del Instituto Internacional del Teatro del Mediterráneo, con el profesor López Estrada, máxima autoridad en el estudio de las encarnaciones poéticas del moro Abindarráez ${ }^{2}$.

Por encima de toda ponderación, en esta línea maurofílica, Cervantes nos descubre en el capítulo 9 de la 1. ${ }^{a}$ Parte del Quijote que el autor de la historia es árabe, un sabio moro, de nombre Cide Hamete Benengeli.

El recurso del autor ficticio y de la historia traducida al castellano de una lengua extraña (aquí, el árabe) procede directamente de los libros de caballerías parodiados en el Quijote. Pero en la pluma de Cervantes adquiere un relieve notable y original.

\footnotetext{
1 Vid. Ángel Ganivet, Obras Completas, I. Ideario español, Madrid, Victoriano Suárez, 1933 (6." edición), pp. 182-183.

2 El Abencerraje y la hermosa Jarifa. Cuatro textos y su estudio por Francisco López Estrada, Madrid, Publicaciones de la Revista de Archivos, Bibliotecas y Museos, 1957, 442 pp. Cfr. Maria de la Soledad Carrasco Urgorti, «El moro de Granada en la literatura (del siglo XV al XX)», Madrid, Revista de Occidente, 1956,500 pp. También es interesante la reseña de este libro de Soledad Carrasco por el mismo López de Estrada en Revista de Filología Española, XL, 1956, pp. 282-286.
} 
En primer lugar, resulta que el árabe no es una lengua exótica y lejana, sino próxima y familiar. En el Alcaná de Toledo, lugar del hallazgo de los cartapacios con el manuscrito de la historia, nos declara el propio Cervantes: "anduve mirando si parecía por allí algún morisco aljamiado que los leyese y no fue muy dificultoso hallar intérprete semejante, pues aunque le buscara de otra mejor y más antigua lengua le hallara»(DQ,I,9), con diáfana alusión al hebreo como lengua sagrada de la Biblia en el Antiguo Testamento.

Resulta curioso el parangón de esta lengua arábiga, en que están escritos los cartapacios toledanos, con las lenguas más desconocidas de las que se presume haber traducido los libros de caballerías. Se habla del griego y del caldeo, que resultan más lejanos que el cercano árabe, lengua que ha legado al castellano común más de cuatro mil palabras. Muchas de ellas ya no se usan y quedan como arcaísmos en el copioso refranero y en la literatura medieval (alaúd, albéitar, alfageme, alfayate), pero son más las que perduran: alcalde, alcuza, alférez, almacén y un largo etcétera.

El mismo Don Quijote da una lección a Sancho Panza sobre los arabismos del castellano: «este nombre albogues es morisco, como lo son todos aquellos que en nuestra lengua castellana comienzan en al, conviene a saber: almohaza, almorzar, alhombra, alguacil, alhucema, almacén, alcancía, y otros semejantes" (DQ,II,67). Claro que toda esta relación no es exacta, ya que almuerzo, por ejemplo, es vocablo de origen latino; pero no se debe exigir a Don Quijote un dominio de la filología moderna.

Cabe suponer que con las palabras árabes han llegado a nosotros instituciones, ideas y conceptos, algunas fórmulas de ver el mundo...

Caso excepcional en la literatura caballeresca es el de Tirante el Blanco, libro muy elogiado por el cura Pero Pérez en el celebérrimo escrutinio de los libros del hidalgo (DQ,I,6). Su autor, Joanot Martorell, asegura en la Dedicatoria que el libro estaba en inglés, fue traducido al portugués y finalmente al valenciano, para que sus convecinos pudieran alegrarse con los regocijantes y eróticos episodios: "m'atreviré expondre, no solament de llengua anglesa en portuguesa, mas encara de portuguesa en vulgar valenciana, per ço que la nació d'on jo só natural s'en puixa alegrar e molt ajudar per los tants e tan insignes actes com hi són» ${ }^{3}$.

${ }^{3}$ Vid. Joanot Martorell-Marti Joan de Galba, Tirant lo Blanc, I, Pròleg i text de Martí de Riquer, Barcelona, Seix Barral, 1969, pp. 113-114. 
En realidad, la única traducción de la novela, por entonces, fue la del valenciano al castellano en Valladolid (1511) y esta versión es la que leyó Cervantes, según deducimos de su entusiasta comentario ${ }^{4}$.

A la singularidad del idioma original en que había sido compuesto el Quijote, añade Cervantes la actividad e intervenciones de Cide Hamete en el curso del relato, sobre todo en su segunda parte, frente a la completa pasividad de los magos e historiadores a quienes se atribuye la invención de los libros de caballerías corrientes. Se advierte, ante todo, en las irrupciones de Cide Hamete, cierto énfasis en las diferencias religiosas de moros y cristianos, con algunas contradicciones e incongruencias. El Quijote apócrifo de Avellaneda, primera y deficiente imitación del cervantino, comienza por atribuir la historia a otro autor arábigo, como lo había hecho Cervantes, aunque sin las consecuencias del verdadero: «El sabio Alisolán, historiador no menos moderno que verdadero, dice que, siendo expelidos los moros agarenos de Aragón, de cuya nación él decendía, entre ciertos anales de historias halló escrita en arábigo la tercera salida que hizo del lugar del Argamesilla el invicto hidalgo Don Quijote de la Mancha.... 5 .

Y aquí termina la misión de Alisolán.

\section{El cautiverio, tema frecuente en los libros de Cervantes}

$¿$ Quiere decir todo lo anterior que los cinco años conflictivos de Cervantes en los baños o prisiones de Argel no cuentan para nada en su creación literaria? La respuesta es absolutamente negativa.

Pero la huella que han dejado no es en la Weltanschauung de Cervantes, en su cosmovisión, que ya estaba impregnada de semitismo por la propia cultura materna, sino en motivos de carácter más externo.

Se advierte en episodios, lances y percances; incluso en recuerdos personales, que se perpetúan en las Novelas Ejemplares

4 Cfr. Tirante el Blanco. Versión castellana impresa en Valladolid en 1511. Edición, introducción y notas de Martín de Riquer, Madrid, Espasa-Calpe, 1974, 5 vols. Col. Clásicos Castellanos, núms. 188-192.

5 Vid. Alonso Fernandez de Avellaneda, Don Quijote de la Mancha. Edición, introducción y notas de Martín de Riquer, Madrid, Espasa-Calpe, 1972, tomo I, cap. $1 .^{\circ}$, p. 19. La obra completa ocupa tres vols. de la Col. Clásicos Castellanos, núms. 174, 175 y 176. También es recomendable la edición de Avellaneda con introducción y notas de Fernando García Salinero en Clásicos Castalia, núm. 41 (Madrid, 1972). 
(El amante liberal, La española inglesa), las comedias de cautivos (El trato de Argel, Los baños de Argel, El gallardo español, La gran sultana) y, señaladamente, en las obras mayores: Don Quijote (I,39-41; II,54,63 y 65) y Los trabajos de Persiles y Sigismunda (libro $3 .^{\circ}$, caps. X y XI).

Sin olvidar que en el primero de sus libros, La Galatea (libro $2^{\circ}$ ) el relato de Timbrio y Silerio incluye un recuerdo edulcorado del asalto de las naves berberiscas que apresaron a Cervantes en $1575^{\circ}$.

Armando Cotarelo Valledor publicó un detallado Padrón literario de Cervantes (1948), seguido de una nómina de personajes históricos mencionados en sus obras. Una de las conclusiones es que el personaje histórico más veces mencionado o aludido por Cervantes es precisamente Mahoma, al que siguen en orden descendente Alejandro Magno, Carlos V, Ovidio, Virgilio, Lope de Vega, Catón, el Cid, Don Juan de Austria, el Conde de Lemos, etc. «Sucesión que demuestra lo que Cervantes quería ser él mismo: un alumno de Marte disputado por Apolo" ?.

A veces, la mención es burlesca, como al hablar de los milagros de Mahoma (DQ,I,5), frase proverbial con sus adláteres populares («los milagros de Mahoma, que salió del sol y se quedó a la sombrax), lo que indica cierta familiaridad y confianza con el profeta de Aláh. También los cristianos ponderan profanas trifulcas con alusiones religiosas: "se armó la de Dios es Criston. Ni debemos olvidar que la exclamación familiar española de Ojalá es un arabismo (wa za Allah) de uso frecuente, con la significación de Dios lo quiera (exactamente «y quiera Dios»). Sólo que aquí el nombre de Dios se da en árabe, emparentado con el Elohá o Elohim de la Biblia. Recurriendo a una etimología vulgar podríamos decir que con la exclamación Ojalá se implora que el ojo de Alá se proyecte sobre lo deseado vivamente por nosotros.

De la posición de Cide Hamete Benengeli ante los milagros y sucesos mágicos o sobrenaturales en el Quijote se ha ocupado recientemente Juergen Hahn, profesor de la Universidad de Stanford en California. De su jugoso librito acerca de Cide

- Cfr. Alonso Zamora Vicente, «El cautiverio en la obra cervantina», Homenaje a Cervantes. Lo dirige y edita Francisco Sánchez-Castañer, Valencia, Mediterráneo, 1950, tomo II, pp. 384-401. Y Alberto SAnchez, Contraluz del cautiverio en la obra literaria de Cervantes, Madrid, Publicaciones del Instituto Nacional de Bachillerato *Cervantes», 1973, 26 pp.

7 Vid. Armando Cotarelo Valledor, Padrón literario de Miguel de Cervantes Saavedra, seguido de una nómina de los personajes historicos mencionados en sus obras y un apéndice de los aprobadores de ellas, Madrid, Publicaciones del Instituto de España, 1948, pp. xiv-xv. 
Hamete, nos interesan ahora dos afirmaciones importantes: $\left.1 .{ }^{a}\right)$ los cristianos del siglo XVI llamaban secta al Islam, sin considerarlo como una religión aparte, sino como una desviación herética predicada por Mahoma; y se advertían en ella una serie de préstamos de la doctrina judeo-cristiana, ya que aceptaban a los profetas del Antiguo Testamento y también a Jesús y María, con explícitas salvedades.

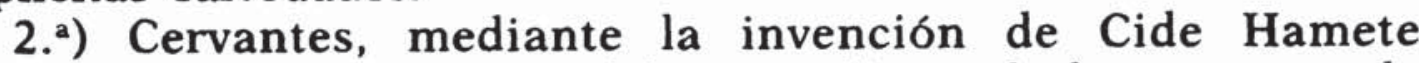
Benengeli, adopta un tanto del racionalismo de los moros y de este modo se alinea con una añeja tradición castellana que empieza en el siglo xIII con la llamada escuela de traductores de Toledo, que expande chispazos de la cultura oriental en el ámbito europeo ${ }^{8}$.

Por tanto, creo que atribuir las repetidas menciones de Mahoma al legado del cautiverio argelino es algo ingenuo y gratuito. Es lo que hacía Cotarelo con énfasis digno de mejor causa en el libro citado anteriormente: "Tampoco carece de interés hallar que el personaje histórico más veces aludido sea Mahoma. ¡Hasta tal punto ahondó en su vida el dardo trágico de Argel!» 9.

Para mí, esta constante mahometana es otra consecuencia de la boga literaria maurofílica, depurada por la sensibilidad y el genio de Cervantes.

\section{LIBERTAD FRENTE A CAUTIVERIO}

A mi juicio, la motivación suprema inspirada por el cautiverio en un espíritu superior como el de Cervantes, nada proclive al desánimo, la abulia o el resentimiento, deriva hacia la exaltación de la libertad como anejo insustituible de la dignidad humana.

El poeta y académico Luis Rosales cifró en la libertad la «clave decisiva del pensamiento cervantino». Cervantes y la libertad es su obra más importante, en dos gruesos volúmenes ${ }^{10}$. Por supuesto, según enfoques de carácter general, bastante alejados del esquema que me propongo desarrollar en estas líneas.

En la fundamentación cuarta de su libro (II), recopila Rosales nada menos que 42 textos cervantinos de referencia al tema

${ }^{8}$ Vid. Juergen Hahn, Miracles, duels, and Cide Hamete's Moorish Dissent, Potomac, Maryland (USA), Scripta Humanistica, 100, 1992.

9 Vid. A. Cotarelo Valledor, obra citada en la nota 7 , p. xiv.

10 Vid. Luis Rosales, Cervantes y la libertad. I-II, La libertad soñada. Prólogo de don Ramón Menéndez Pidal, Madrid, Sociedad de Estudios y Publicaciones, 1960, 2 vols. 
( $\sin$ comentarios adicionales en una serie miscelánea), ampliando notablemente los 16 aducidos por Américo Castro y convenientemente clasificados en su libro fundamental sobre $E l$ pensamiento de Cervantes ${ }^{11}$.

Pero ninguno de estos dos libros recoge el texto aportado en cabecera por Heinz-Peter Endress, precisamente al analizar la libertad (Freiheit) como uno de los ideales básicos en Don Quijote ${ }^{12}$.

Para mi teoría es una cita de gran valor, procedente de Los tratos de Argel (jornada 2. ${ }^{a}$ ), cuando Aurelio canta las excelencias de la mítica Edad de Oro en la aurora de la Humanidad:
¡Cuán seguros y libres discurrieron
la redondez del suelo los que en ella
la caduca mortal vida vivieron!
No sonaba en los aires la querella
del misero cautivo, cuando alzaba
la voz a maldecir su dura estrella.
Entonces libertad dulce reinaba,
y el nombre odioso de la servidumbre
en ningunos ofdos resonaba.

La libertad es un elevado concepto, recurrente a lo largo de toda la creación cervantina y unida en ocasiones a su odiosa contrafigura de la esclavitud o el cautiverio.

Ya en la primera obra, La Galatea (libro 6. ${ }^{\circ}$ ), el terceto final de un celebrado soneto de la desamorada Gelasia lo proclama rotundamente en un vibrante epifonema:

Del campo son y han sido mis amores; rosas son y jazmines mis cadenas:

libre nasct $y$ en libertad me fundo.

Un eco amplificado resuena en el discurso de la pastora Marcela: «Yo nací libre y para poder vivir libre escogí la libertad de los campos» (DQ,I,14).

A la libertad de la vida en el campo, lejos de las barreras e intrigas de la ciudad, se refiere el gitano viejo que canta las ventajas de la vida suelta de su raza en la primera de las «novelas ejemplares» cervantinas: La gitanilla. Con su secuencia de

"Vid. Américo Castro, El pensamiento de Cervantes, Madrid, Ed. Hernando, 1925. Anejo VI de la Revista de Filología Española; 2." edición, ampliada con notas de Rodríguez Puértolas (Barcelona, Ed. Noguer, 1972). Edición facsímil de la 1." en Ed. Crítica, dirigida por Francisco Rico (Barcelona, 1987).

12 Vid. HeInz-Peter EndRess, Don Quijotes Ideale Im Umbruch der Werte vom Mittelalter bis zum Barock, Tübingen, M. Niemeyer Verlag, 1991, pp. 78-82. 
gitanos y gitanas en la comedia de Pedro de Urdemalas y el cuadro más realista de la vida gitanesca en el Coloquio de los perros, última de las «ejemplares». La gitanilla y el Coloquio son alfa y omega de la celebrada serie que acredita a Cervantes como el creador en España de la novela corta, de larga e ilustre descendencia.

Y es la seudo-gitana Preciosa quien se manifiesta en el mismo rumbo que sus hermanas mayores Gelasia y Marcela: «mi alma, que es libre y nació libre, y ha de ser libre en tanto que yo quisiere...» Notable reiteración trimembre.

Una vez más Cervantes se siente atraído por los personajes desarraigados o las minorías marginales y perseguidas. Son tres las que llaman primordialmente su atención humana y estética: judíos, gitanos y moros o moriscos.

Es evidente que de los tres grupos $\longrightarrow$ naciones, como se les llamaba entonces- el tratado con más extensión y simpatía es el de los moros y moriscos, en armonía con el sentimiento popular más difusamente arraigado.

La expulsión de los judíos en 1492 no tuvo la repulsión general que alcanzó la de los moriscos en 1609. Cervantes escribía entonces la segunda parte del Quijote, donde registra el suceso con emocionantes rasgos (DQ,II,54,63 y 65). También lo hace en e Persiles $\left(3 .^{\circ}, \mathrm{X}\right)$ y en el Coloquio de los perros, pero con diversos matices. Los cervantistas se han esforzado en interpretar la auténtica opinión de Cervantes ante el controvertido decreto de Felipe III, que ordenaba la expulsión. No han llegado a un acuerdo, ya que las conclusiones son antagónicas. Francisco Márquez Villanueva ha estudiado el problema con profundidad y solvencia; cree que Cervantes, en el fondo, era opuesto a la drástica disposición, emanada de una mal entendida «razón de Estado» ${ }^{13}$.

Lo que aparece muy patente es que el tema de la libertad, estimado desde las primeras obras, alcanza su clímax en los últimos años de la creación cervantina.

\section{Libertad y CAUTIVERIO EN EL QUIJOTE}

Ya desde el prólogo de la 1." parte vemos planteado el insoslayable oxymoron, a propósito de un dictum clásico y manido

13 Francisco Marouez Villanueva, «El morisco Ricote y la hispana razón de Estadon, en Personajes y temas del Quijote, Madrid, Taurus, 1975, pp. 229-235; y su libro más reciente El problema morisco desde otras laderas, Madrid, Edics. Libertarias, 1991, 327 pp. 
sobre la libertad: «como será primero, tratando de libertad y cautiverio:

Non bene pro toto libertas venditur auro» ${ }^{14}$.

En esta dirección, es terminante la frase del Capitán Cautivo: "que no hay en la tierra contento que se iguale al de alcanzar la libertad perdida» (DQ,I,39). Tras la firme convicción, adivinamos al propio Cervantes respirando por la herida de su experiencia más amarga.

La más explícita y ponderada exposición del principio la oímos de labios del mismo Don Quijote:

«La libertad, Sancho, es uno de los más preciosos dones que a los hombres dieron los cielos; con ella no pueden igualarse los tesoros que encierra la tierra ni el mar encubre; por la libertad, asi como por la honra se puede y debe aventurar la vida; y, por el contrario, el cautiverio es el mayor mal que puede venir a los hombres» (DQ,II,58).

En este discurso Don Quijote alcanza la máxima elocuencia por la autenticidad de lo vivamente sentido y experimentado. Se reitera la noción de cautiverio, como supremo desafío a la dignidad humana, frente a la de libertad, como valor espiritual inestimable.

Pero ocurre que el término libertad puede esgrimirse con intenciones espurias y Cervantes nos previene contra ellas. El mismo Don Quijote nos lo advierte en un ejemplo cuya vigencia llega hasta nuestros días.

En uno de sus discursos más sustanciosos y menos comentados, sostiene que debe remediarse la situación económica del soldado pobre, «viejo y estropeado", es decir, del mutilado de guerra en la ancianidad llena de penuria (léase la situación del mismo Cervantes, muy conocido como el «manco de Lepanto»). No sin devota admiración, leemos la justa advertencia del caba-

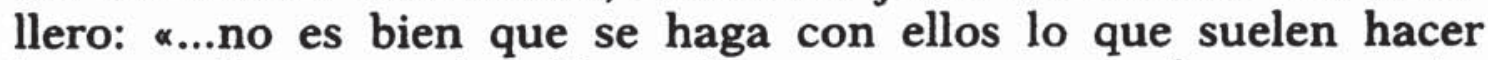
los que ahorran y dan libertad a sus negros cuando ya son viejos y no pueden servir, y echándolos de casa con título de li-

14 En la meritoria compilación moderna Aurea dicta, «dichos y proverbios del mundo clásicon, con introducción de E. Tierno Galván y selección de Eduardo Valentí (Barcelona, Ed. Crítica, 1987, p. 381) se recoge la sentencia en cabecera del capitulo dedicado a la libertad y se añade la traducción de Neus Falí: «la libertad no se paga ni con todo el oro del mundo». También se documenta el origen, festivamente trabucado por Cervantes, que la atribuye «a Horacio, o a quien lo dijo» (¿qué más da?). Es el primer verso de un dístico de las Fabulae Aesopicae, 54, 25. 
bres, los hacen esclavos de la hambre, de quien no piensan ahorrarse sino con la muerte» (DQ,II,24).

Mutatis mutandis, esta argumentación fue esgrimida en los años veinte de la centuria actual por un jefe revolucionario de notorio relieve ( $\propto$ Libertad, ¿para qué? ¿para morirse de hambre?»). En su virtud, he podido considerar a Don Quijote como paladín adelantado de la justicia social ${ }^{15}$.

Mención ambigua, discutida y discutible todavía, es la de la libertad en labios de Don Quijote en la liberación de los galeotes, condenados por la justicia positiva a trabajos forzados en las galeras del rey. Aquí el caballero da por sentado que los juicios legales condenatorios pueden haber sido torcidos o maleados. Y decide por su cuenta, en única instancia y no poco riesgo en una sociedad organizada, dejar en libertad a los presos, "porque me parece duro caso hacer esclavos a los que Dios y naturaleza hizo libres» (DQ,I,22).

Esta decisión, por supuesto, ha sido extraordinariamente debatida, pero no podemos detenernos en su examen. En último término, no debe considerarse como anárquico el proceder del caballero, sino como actuación delirante en busca de la justicia absoluta. Basta unir este caso al anterior para contemplar dos criterios muy equívocos en el uso indiscriminado del concepto de libertad.

De carácter muy distinto, aunque igualmente controvertido, es la libertad de conciencia, alegada por el morisco Ricote (DQ,II,54).

A partir del siglo XIX, la libertad de conciencia es ampliamente admitida como uno de los derechos humanos inviolables. Pero no ocurría así en los tiempos de Cervantes.

El cervantista Joaquín Casalduero ha destacado el valor negativo de esta expresión en boca del morisco: resalta la presencia de esta libertad en Alemania, «porque sus habitadores no miran en muchas delicadezas». Censura como anacrónicas las interpretaciones de este punto que vienen a considerar a Cervantes como un precursor de los librepensadores europeos del siglo $\mathrm{XIX}^{16}$.

Como destaqué hace tiempo, la ortodoxia cristiana del Siglo

15 Cfr. mi ensayo «La sociedad española en el Quijote», Suplementos de Anthropos (17), «Miguel de Cervantes en su obra: antología, selección de estudios y documentación», Barcelona, sept. 1989, p. 274. Ha sido traducido al alemán, con el título de «Don Quijote und die Spanier», en el catálogo de la exposición bibliográfica Don Quixote. Ausgaben in vierhundert Jahre, Madrid, Biblioteca Nacional-Frankfurt am Main, Museum für Kunsthandwerk, 1991, pp. 13-35.

16 Vid. Joauuin Casalduero, Sentido y forma del Quijote (1605-1615), Madrid, Edics. Insula, 1949, pp. 329-332. 
de Oro rechazó en absoluto la peligrosa innovación de la libertad de conciencia. No se puede admitir libremente el error ni el delito. El P. Rivadeneira, S.J., en el Tratado de la religión y virtudes del príncipe cristiano (1601) y Covarrubias en su Tesoro de la lengua castellana o española (1611), por citar solamente dos autoridades del momento, califican de servidumbre del alma a la libertad de conciencia, e incluso crimen pestilencial digno de los más severos castigos ${ }^{17}$.

A mi entender, debe tenerse en cuenta todo el contexto amable del discurso de Ricote con sus lágrimas por la pérdida de la patria natural (España), ya que en ella había nacido. También es significativo que no aparezcan los sobados dicterios ortodoxos contra la libertad de conciencia, considerada tímidamente en el Quijote como falta de delicadeza simplemente.

Por otra parte, me ha parecido encontrar un posible ejemplo de esa libertad denostada en la actitud de Zoraida, la enamorada del capitán cautivo (DQ,I,40-41). Bien sabida es la decisiva ayuda que presta a Ruy Pérez de Viedma para escapar del cautiverio. Sale con él decidida a bautizarse cristiana para después contraer matrimonio. Pero Agi Morato, padre de Zoraida, los sorprende en su huida y se ven obligados a llevárselo a la fuerza, para abandonarlo más tarde, en una playa desierta.

Azorín ha evocado la situación en tonos patéticos: «iHay que ver la escena conmovedora, intensamente conmovedora, del padre en la playa, viendo cómo su hija, su única hija, su amada hija, se va alejando hacia una tierra de donde ya no volverá! ¡Hay que ver cómo se arranca los cabellos, cómo se mesa las barbas, cómo se revuelve en la arena y cómo da al viento sus lamentos doloridos! ${ }^{18}$.

Pero no ha tenido en cuenta el trasfondo de la inevitable separación. Agi Morato, según nos ilustró el eminente arabista Oliver Asín, es una figura histórica en Argel a finales del siglo xVI. "Su nombre es propiamente no más que Murad o Morato, nombre muy divulgado entre los turcos, desde el momento en que lo habían llevado célebres sultanes de Constantinopla. "Agi», o sea hayyyi, era el título honorífico que daban a todo aquel que, como Murad, había hecho la peregrinación a La Meca» ${ }^{19}$. Goza,

17 Cfr. Alberto SÁnchez, «Temas recurrentes en el Quijote de 1615», en Cervantes: su obra y su mundo, Ed. M. Criado de Val, Madrid, Edi-7, 1981, pp. 479-483.

18 Vid. Azorin, «Cervantes y Zoraida», en Con permiso de los cervantistas, Madrid, Biblioteca Nueva, 1948, p. 40.

19 Vid. Jaime Olver Asfn, La hija de Agi Morato en la obra de Cervantes, Madrid, Aguirre Imp. (Bol. RAE), 1948, p. 12. 
por tanto, de cierta preeminencia religiosa en la sociedad musulmana. En el fondo, quizá sienta más que su hija abandone el Islam, la creencia en la que ha sido educada, y se convierta al cristianismo, que deje a su padre para siempre.

Pero la hija única y mimada explica su resolución al padre abatido: «Alá sabe bien que no pude hacer otra cosa... según la priesa que me daba mi alma a poner por obra ésta que a mí me parece tan buena como tú, padre amado, la juzgas por mala" (II,41).

Esta réplica ha sido juzgada por Spitzer como otro ejemplo de perspectivismo o realidad oscilante en el Quijote ${ }^{20}$, comparable en cierto modo a la afirmación de Don Quijote: "eso que a ti te parece bacía de barbero, me parece a mí el yelmo de Mambrino, y a otro le parecerá otra cosa» $(I, 25)$.

Creo francamente que no son ejemplos comparables, puesto que la esfera del conocimiento sensorial no puede equipararse a la más íntima del sentimiento religioso, independiente de los argumentos racionales. Precisamente, en la novela del Curioso impertinente, intercalada en el primer Quijote (I,33-35) se pone de manifiesto que a los moros «no se les puede dar a entender el error de su secta con las acotaciones de la Santa Escritura, $n i$ con razones que consistan en especulación del entendimiento, ni que vayan fundadas en artículos de fe, sino que se les han de traer ejemplos palpables, fáciles, inteligibles, demostrativos, indubitables con demostraciones matemáticas que no se pueden negar...» (I,33).

Como ha documentado, con fina agudeza, la profesora Otilia López Fanego, fue un intento muy característico de la crisis religiosa del pensamiento en la primera mitad del siglo xVI demostrar las verdades religiosas more mathematico ${ }^{21}$. Intento racionalista extraviado en el laberinto perdurable de la razón y la fe.

Si no nos parece adecuado hablar de perspectivismo en las premisas expuestas, ¿cómo explicar la réplica de Zoraida a su padre? ¿gracia sobrenatural? ¿libertad de conciencia? ¿y la invocación a Dios, todavía como Alá? Plantea oblícuamente la gran cuestión de la religión verdadera, el tema inquietante que habría de inspirar a Unamuno su preciosa novelita de San Manuel Bueno, mártir (1931).

No podemos detenernos por más tiempo en elucidar tan delicadas cuestiones. Baste por ahora el haber señalado las diferen-

20 Vid. Leo SPITZER, «Perspectivismo lingúistico en el Quijote», en Lingǘstica e Historia Literaria, Madrid, Ed. Gredos, 1955, pp. 161-225.

21 Vid. Otilia LOPEz FANego, «Nota a una alusión cervantina», en Anales Cervantinos, XIII-XIV, 1974-1975, pp. 161-164. 
cias históricas en la matización de la libertad y en los sinuosos repliegues de su concepción.

Y terminar reiterando la contraposición cervantina de libertad y su oscuro reverso, manifestado en cualquier modalidad de cautiverio y servidumbre. De tal propuesta se desprende la constante cervantina en defensa de la libertad como privilegio inherente al espíritu y fundamento insustituible de la dignidad humana.

Alberto Sánchez 